\title{
Andersen's model on determining the factors associated with antenatal care services in Nepal: an evidence-based analysis of Nepal demographic and health survey 2016
}

Bidusha Neupane ${ }^{1}$, Sujan Rijal², Srijana G.C. ${ }^{1}$ and Til Bahadur Basnet ${ }^{3^{*}}$ (i)

\begin{abstract}
Background: With the formulation of the National Safe Motherhood Policy in 1998, safe motherhood has forever been a priority program in Nepal. Under the safe motherhood program, every woman is provided with essential maternal health care services until now through the four-tire district health care system. There is a considerable increase in the utilization of antenatal care (ANC) by a skilled health provider from 2011 to 2016, 58 to 84\%, respectively. However, inequality, exclusion, and under-utilization in health care services continue in many regions of Nepal. The present study aimed to explore the different types of socio-demographic factors associated with current ANC service utilization in Nepal.
\end{abstract}

Methods: A cross-sectional study was conducted using the Nepal Demographic and Health Surveys data (DHS-7, 2016-2017). We estimated the latest pregnancy and live births in recent 5 years with the utilization of ANC services, and socio-economic differentials in these indicators under the framework of the Andersen behavioral model.

Results: Two in three (69.8\%) with last birth accessed at least four ANC visits. The rate of live birth was about $98.6 \%$ in the ANC4+ group, higher than that of $96.8 \%$ in the ANC4- group ( $x 2: 14.742, P<0.001$ ). In the multilevel logistic regression analysis, we found that women from province 2 (OR: $0.48 ; 95 \% \mathrm{Cl}$ : $0.32-0.74$ ) and province 6 (OR: 0.46 ; 95\%Cl: 0.30-0.71) were significantly less likely to visit ANC 4 or more times. Age (OR: 0.95; 95\%Cl: 0.93-0.96) was also significantly associated with the frequency of ANC visits. Level of Women's education and education of her partner were both significantly associated with the ANC visits: women (OR: 4.64; 95\%Cl: 3.05-7.05) and her partner (OR: 1.45; 95\%Cl: 1.01-2.06) having higher education were most likely to go for the recommended number of ANC visits. Moreover, women having exposure to multimedia were more likely to go for four or more ANC check-ups.

Conclusions: The results highlight the need for governments and health care providers to develop special health promotion program with a focus on the vulnerable and disadvantaged and to use multi-media for maternal health literacy improvement flexibly, and maternal health system strengthening.

Keywords: Antenatal care, Equality, Health utilization, Andersen behavioral model

* Correspondence: ddst19basnet@hotmail.com

${ }^{3}$ BP Koirala Institute of Health Science, Dharan, Nepal

Full list of author information is available at the end of the article

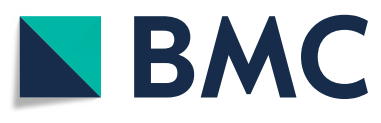

(c) The Author(s). 2020 Open Access This article is licensed under a Creative Commons Attribution 4.0 International License, which permits use, sharing, adaptation, distribution and reproduction in any medium or format, as long as you give appropriate credit to the original author(s) and the source, provide a link to the Creative Commons licence, and indicate if changes were made. The images or other third party material in this article are included in the article's Creative Commons licence, unless indicated otherwise in a credit line to the material. If material is not included in the article's Creative Commons licence and your intended use is not permitted by statutory regulation or exceeds the permitted use, you will need to obtain permission directly from the copyright holder. To view a copy of this licence, visit http://creativecommons.org/licenses/by/4.0/. The Creative Commons Public Domain Dedication waiver (http://creativecommons.org/publicdomain/zero/1.0/) applies to the data made available in this article, unless otherwise stated in a credit line to the data. 


\section{Background}

\section{Global context}

An estimate from United Nations International Children's Emergency Fund (UNICEF) in 2015 depicts that 800 women and 2700 newborns died every day due to the complication of pregnancy and childbirth. ANC and delivery by the skilled attendant are vital to prevent such deaths [1]. Compared to 59\% in 1990, women in 2015 had more access to antenatal care services, where $71 \%$ of total women in the world can get access to antenatal care services [1]. Maternal deaths are being increasingly concentrated in sub-Saharan Africa and some South Asian nations, the nations that lack quality services [1]. Disparities exist all over the world in terms of access to service with poor, uneducated women coming from the lower wealth quintile having less access to much need $\mathrm{ANC}$, and the disparity on access has not changed in the last 15 years. Hence, concrete and specific work addressing the issues related to inequality is needed to narrow this gap [1].

According to World Health Organization (WHO) Global Health Observatory, in 83 countries, $75 \%$ of women had at least four times ANC check-ups, while $86 \%$ of women had received ANC checkup at least once by the skilled professionals. In developed countries like the United States, France, and Canada, the figure ranges above 80 to $100 \%$. While the statistics are quite different for developing nations, including African and some Asian countries, the number ranges from somewhere between 50 and $60 \%$ [2, 3]. A report published by WHO mentions that death due to maternal-related causes in a developing country is $33 \%$ higher than for women living in a developed country [2].

In 2015, Maternal Mortality Rate (MMR) in developing countries was 239 pregnant women per 100,000 live births, compared with 12 per 100,000 in developed countries [4]. While almost all pregnant women in highincome countries have had at least four prenatal visits, only $40 \%$ of pregnant women in low-income countries have received more than four prenatal care [5]. The MMR of the world decreased by $52.0 \%$ between 1980 and 2015, which indicated that the public health policy failed to meet the requirement of reducing the threequarters of the Millennium Development Goals (MDGs). Currently, Sustainable Development Goals (SDGs) have a high ambition to reduce maternal mortality to less than 70/100,000 live births by 2030, with an annual decline rate of at least $7.5 \%$ [6]. Thus, there is a need for more focused intervention to save the lives of mothers and children. Evidence suggests that ANC checkup in the past has substantially contributed a lot to address the issues; an improved ANC checkup could potentially mean a better maternal and child health outcome [5-7]. For instance, at least four ANC visits, which include blood pressure measurement, blood, and urine tests and advice on pregnancy complications and advice on where to go if such complications, has shown to decrease the risk of neonatal mortality $[8,9]$. In an Indian study, compared to women who had neonatal deaths, women who had given live birth had received better quality recommended number of ANC [10].

\section{Nepal's context}

With the formulation of the National Safe Motherhood Policy in 1998, safe motherhood has forever been a priority program in Nepal. Under the safe motherhood program, every woman is provided with essential maternal health care services until now through the four-tire district health care system [11]. Due to the intense policy action which attracted a lot of programs and fund in the field of maternal and child health care, we have managed to increase the coverage of maternal health services over the years [12-14]. With such an implementation of effective policy, Nepal has been one of the few low- and middle-income countries that achieved several MDGs well before 2015 with an increase in the utilization of ANC by skilled health providers from 2011 to 2016, 58 to $84 \%$ respectively [15]. However, inequality, exclusion, and under-utilization in health care services continue in regions of Nepal [16]. Almost 15\% of Nepalese women reported no ANC visits, and only half (50\%) reported four or more ANC visits, The recommended number of visits is not always met [17]. A study conducted in Nepal (2013) revealed that educated women of younger age whose husbands were also educated, living in urban areas, from non-farming occupations and falling in higher wealth quintiles were more likely to attend four or more ANC and receive higher quality ANC [8]. Very few studies focus on the quality of ANC in low-income countries like Nepal, and most of them have focused only on individual factors $[18,19]$. The present study was conducted to explore different types of contextual and individual factors associated with current ANC service utilization in Nepal, to provide evidence-based information to address the problems more precisely on improving the equity and coverage of essential maternal health service utilization.

\section{Conceptual framework}

The framework of the Andersen behavioral model was adopted for classifying the factors associated with ANC visits. This multilevel model incorporated individual and contextual determinants of health services use and was developed by Ronald M. Andersen in 1968 and advanced in 1990 (the fourth version) [20, 21]. It had different layers, including the external environment, population characteristics, and health behavior, and health outcome (Fig. 1). 


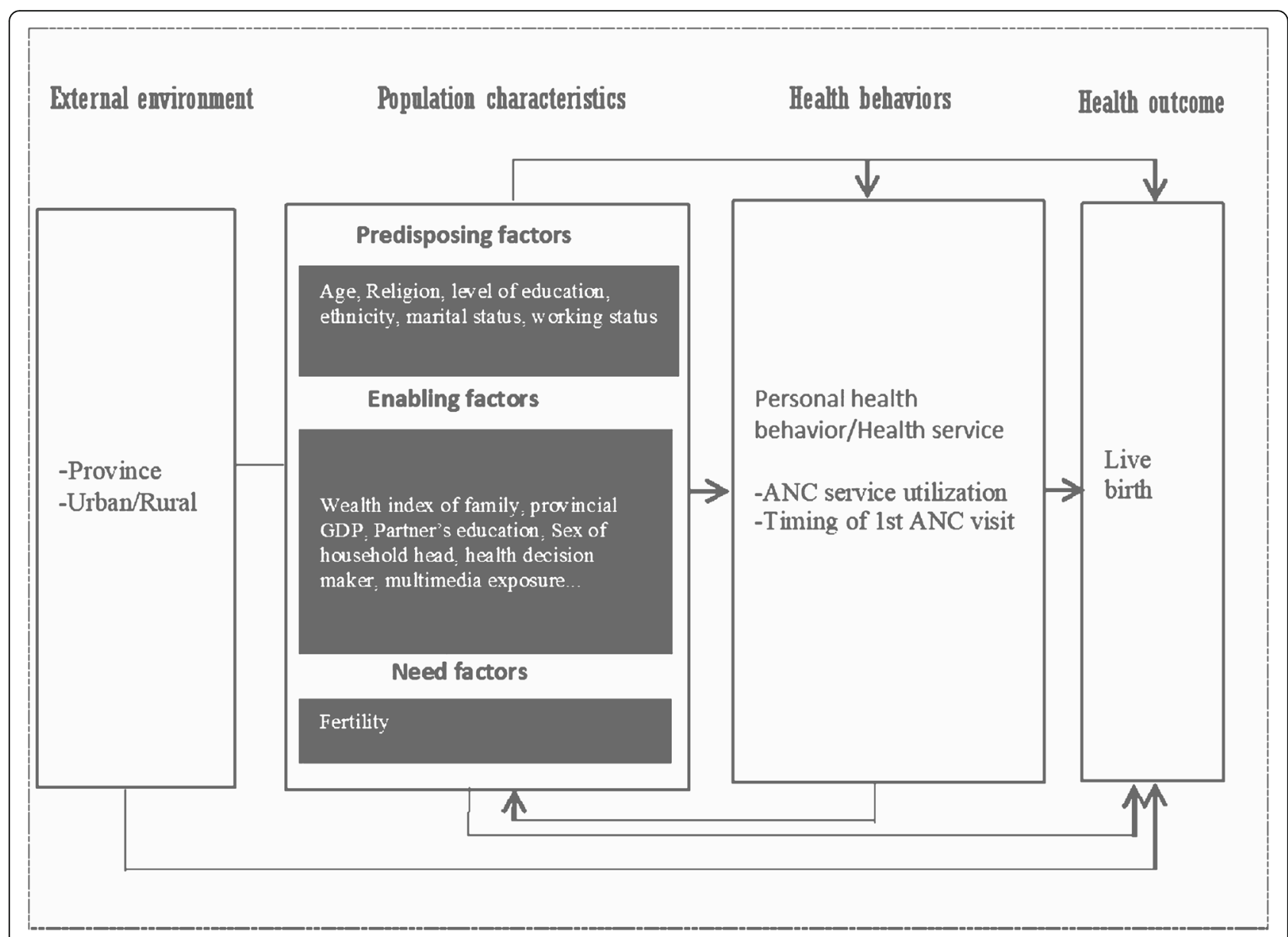

Fig. 1 Conceptual Framework of Anderson behavioral model. GDP: Gross domestic product; ANC: Antenatal care

\section{Methods}

\section{Data source}

We used data from the 2016 Nepal Demographic and Health Survey (NDHS), which is a national level household survey. Under the Ministry of Health, the survey began in June 2016 and lasted until January 2017. A total of 11,473 households were selected for the sample, where, 11,203 were occupied. From those households, 11,040 were successfully interviewed. Among the interviewed households, 13,089 women age 15-49 were identified for individual interviews; interviews were completed with 12,862 women, with a response rate of $98 \%$. We restricted our analyses to individual women age 15-49 of reproductive age who given birth 5 years before NDHS 2016. Women of age group 15-49 selected for the study either were permanent residents of the household selected for an interview or an eligible visitor who had stayed there a night before the survey [15].

The data collection for the NDHS, 2016, was ethically approved by the Nepal Health Research Council (NHRC), which is a national level government organization leading in research activities in Nepal.
Similarly, ethical clearance was also obtained from ICF Macro Institutional Review Board, Maryland, USA. Data were collected after an online application was submitted to the demographic health survey (DHS) program explaining the purpose of the study, intended use, and people who would have access over the data [15]. After the review of the online application, permission had been obtained from the monitoring and evaluation body of DHS globally, MEASURE DHS, to use the data set for this study. The NDHS, 2016 data are publicly available at the USAID DHS program (at http://dhsprogram.com/ data) in different formats.

\section{Outcome variable}

Our outcome variable was the attendance of at least four or more times ANC (ANC 4+) which is the recommended number of ANC visits by WHO.

\section{Study variables}

Altogether 15 variables relevant to the study were selected and divided into contextual factors and individual factors [22, 23]. Nepal has recently adopted the federal 
system of government, whereby the formal names of the provinces are yet to be decided, hence, they are still known by numbers through 1 to 7 . Province of residence, place of residence (urban/rural), age of the women, ethnicity (Brahmin/Chettri, Janjati, Dalit, Muslim and others), religion (Hindu, non-Hindu), women's education (no education, primary, secondary and higher), partner's education (no education, primary, secondary and higher), respondent's occupation (didn't work, skilled worker, unskilled worker, and agriculture), household wealth index (poor, middle class, rich), provincial GDP, sex of household head (male, female), health care decision-maker (women herself, herself along with someone else, solely others), exposure to the newspaper (not at all, less than once a week, at least once a week), exposure to the radio (not at all, less than once a week, at least once a week) and exposure to television (not at all, less than once a week, at least once a week).

\section{Statistical analyses}

A total of 4006 ever-married women between 15 and 49 years were eligible to be included in our study. We estimated the latest pregnancy and live birth in recent 5 years with the utilization of ANC service and the socioeconomic differentials in these indicators by age, work, residence, religion, wealth, media exposure were analyzed using a multilevel logistic regression model.

The variables were divided as per the need for predisposing and enabling factors. After that, descriptive statistics were performed to find the frequency of various independent variables. A Chi-square test was executed to find the relation between the dependent variables $(\mathrm{ANC}+)$ and the outcome variable (live birth). Furthermore, the variables were divided into contextual factors and individual factors for further analyses. Province, provincial GDP, household wealth index, religion, and ethnicity were considered as the contextual factors while the rest were the individual factors. Since GDP was not available from NDHS, the GDP of 2011 was taken from a data source that contains data related to Nepal [24]. The multilevel nested structure of analysis comprised 4006 individuals (level 1) grouped into 380 primary sampling units (PSUs), which were wards in rural areas and enumerator areas in the urban area (level 2). Again, the PSUs were nested into the place of residence (urban and rural area) (level 3). Multilevel logistic regression was performed to test the association of contextual and individual independent variables with the number of $4^{+}$ANC visits in Nepalese pregnant women. Variables associated with $4^{+} \mathrm{ANC}$ at a significant level $p<.05$ were considered for the multivariable analysis. A three-level random intercept and fixed-slopes model structure with individuals nested within PSUs and PSUs within urban-rural cities were fitted to estimate the odds ratios (OR) and
95\% CIs, indicating the likelihood of having a higher mean of $4^{+}$ANC visit. The overdispersion of the data was handled by using a three-level random intercept model.

Stepwise forward selection of variables in subsequent models was conducted to obtain a parsimonious final model for ANC visit, according to the theoretical framework (Fig. 1). The first and second models consisted of contextual predisposing and enabling factors, and the second and third models comprised of individual predisposing and enabling variables, respectively. Variables that remained statistically significant at $5 \%(P \leq .05)$ were retained in the analysis for adjustment in the next model. Thus, the final models included all significant contextual and individual predisposing and enabling factors. The statistical analyses were executed using $\mathrm{R}$ version 3.6.3 with the "lme4" package.

\section{Results}

\section{Respondent's socioeconomic and demographic} characteristics

Table 1 shows the participant's socioeconomic and demographic characteristics. Seventy-five percent of total pregnant women living in urban parts of Nepal went for four or more ANC visits compared to $62 \%$ from rural regions. Similarly, for the province of residence, the percentage distribution of 4 or more times ANC visit was almost the same for provinces $1,3,4,5$ and 7. The percentage was relatively low in province 2 and 6 . There was a significant association of ANC $4^{+}$with the province of residence and if the women came from a rural or urban area $(p<0.001)$.

The percentage of four or more ANC visits was highest (74.1\%) among the 15-19 years age group and lowest among women beyond 35 years of age at $54.1 \%$. The women from the Muslim community were the lowest contributor; at $53.1 \%$ four or more ANC visits. Here, age, ethnicity, level of education, and religion were significantly associated with $4^{+}$ANC use $(p<0.001)$.

Only $65.6 \%$ of the total pregnant women who resided in provinces whose provincial GDP per capita was below the national average (i.e., \$718) went for four or more ANC visits. Likewise, $77.2 \%$ of women with educated partners went for four or more ANC visits. A higher percentage of women, i.e., $94 \%$ of pregnant women with exposure to the newspaper at least once a week, went for four or more ANC visits compared to only $63.6 \%$ of those who did not have access to the newspaper at all. Household wealth index, provincial GDP, partner's education, participation in healthcare decision making, exposure to radio, $\mathrm{TV}$, and newspaper were all significantly associated with ANC 4+ visit $(p<0.001)$.

As many as 3754 women, i.e., $94 \%$ of total women who were pregnant 5 years before the survey, have 
Table 1 Respondent's characteristics divided into environmental, predisposing and enabling factors

\begin{tabular}{|c|c|c|c|c|c|}
\hline Variable & Total & No ANC (\%) & $1-3$ times ANC (\%) & 4+ ANC (\%) & $p$-value \\
\hline \multicolumn{6}{|l|}{ Environmental Factor } \\
\hline \multicolumn{6}{|l|}{ Province } \\
\hline Province 1 & 575 & $26(4.5)$ & $103(17.9)$ & $446(77.6)$ & \multirow[t]{7}{*}{$<0.001$} \\
\hline Province 2 & 759 & $37(4.90)$ & $302(39.8)$ & $420(55.3)$ & \\
\hline Province 3 & 434 & $28(6.5)$ & $70(16.1)$ & $336(77.4)$ & \\
\hline Province 4 & 436 & $29(6.7)$ & $74(17)$ & $333(76.4)$ & \\
\hline Province 5 & 651 & $32(4.90$ & $137(21)$ & $482(74)$ & \\
\hline Province 6 & 602 & $74(12.3)$ & $170(28.2)$ & $358(59.5)$ & \\
\hline Province 7 & 549 & $26(4.7)$ & $103(18.8)$ & $420(76.5)$ & \\
\hline \multicolumn{6}{|l|}{ Residence } \\
\hline Urban & 2338 & $112(4.8)$ & $465(19.9)$ & $1761(75.3)$ & \multirow[t]{2}{*}{$<0.001$} \\
\hline Rural & 1668 & $140(8.4)$ & $494(29.6)$ & $1034(62)$ & \\
\hline \multicolumn{6}{|l|}{ Predisposing Factor } \\
\hline \multicolumn{6}{|l|}{ Age years } \\
\hline $15-19$ & 344 & $10(2.9)$ & $79(23)$ & $255(74.1)$ & \multirow[t]{3}{*}{$<0.001$} \\
\hline $20-29$ & 2657 & $130(4.9)$ & $624(23.5)$ & $1903(71.6)$ & \\
\hline $30-49$ & 1005 & $112(11.1)$ & $256(25.5)$ & $637(63.4)$ & \\
\hline \multicolumn{6}{|l|}{ Ethnicity } \\
\hline Brahmin/Chettri & 1361 & $76(5.6)$ & $241(17.7)$ & $1044(76.7)$ & \multirow[t]{5}{*}{$<0.001$} \\
\hline Janjati & 1266 & $92(7.3)$ & $265(20.9)$ & $909(71.8)$ & \\
\hline Dalit & 584 & $42(7.2)$ & $166(28.4)$ & $376(64.4)$ & \\
\hline Muslim & 229 & $7(3.1)$ & $101(44.1)$ & $121(52.8)$ & \\
\hline Others & 566 & $35(6.2)$ & $186(32.9)$ & $345(61)$ & \\
\hline \multicolumn{6}{|l|}{ Religion } \\
\hline Hindu & 3487 & $225(6.5)$ & $796(22.8)$ & $2466(70.7)$ & \multirow[t]{2}{*}{$<0.001$} \\
\hline Non-Hindu & 519 & $27(5.25)$ & $163(31.4)$ & $329(63.4)$ & \\
\hline \multicolumn{6}{|l|}{ Level of education } \\
\hline No education & 1231 & $153(12.4)$ & $452(36.7)$ & $626(50.90)$ & \multirow[t]{4}{*}{$<0.001$} \\
\hline Primary & 763 & $54(7.1)$ & $215(28.2)$ & $494(64.7)$ & \\
\hline Secondary & 1396 & $40(2.9)$ & $249(17.8)$ & $1107(79.3)$ & \\
\hline Higher & 616 & $5(0.8)$ & $43(7)$ & $568(92.2)$ & \\
\hline \multicolumn{6}{|l|}{ Respondent's Occupation } \\
\hline Didn't work & 1441 & $95(6.6)$ & $347(24.1)$ & $999(69.3)$ & \multirow[t]{4}{*}{0.217} \\
\hline Skilled worker & 466 & $36(7.7)$ & $94(20.2)$ & $336(72.1)$ & \\
\hline Unskilled worker & 114 & $9(7.9)$ & $32(28.1)$ & $73(64)$ & \\
\hline Agriculture & 1985 & $112(5.6)$ & $486(24.5)$ & $1387(69.9)$ & \\
\hline \multicolumn{6}{|l|}{ Enabling Factor } \\
\hline \multicolumn{6}{|l|}{ Wealth Index of family } \\
\hline Poor & 1879 & $200(10.6)$ & $520(27.7)$ & $1159(61.7)$ & \multirow[t]{3}{*}{$<0.001$} \\
\hline Middle & 822 & $22(2.7)$ & $225(27.4)$ & $575(70)$ & \\
\hline Rich & 1305 & $30(2.3)$ & $214(16.4)$ & $1061(18.3)$ & \\
\hline \multicolumn{6}{|l|}{ Provincial GDP per capita (\$) (USD) } \\
\hline < 718 (national average) level) & 2561 & $169(6.6)$ & $712(27.8)$ & $1680(65.5)$ & \multirow[t]{2}{*}{$<0.001$} \\
\hline $718-1000$ & 1011 & $55(5.4)$ & $177(17.5)$ & $779(77.1)$ & \\
\hline
\end{tabular}


Table 1 Respondent's characteristics divided into environmental, predisposing and enabling factors (Continued)

\begin{tabular}{|c|c|c|c|c|c|}
\hline Variable & Total & No ANC (\%) & $1-3$ times ANC (\%) & $4+$ ANC (\%) & $p$-value \\
\hline$>1000$ & 434 & $28(6.5)$ & $70(16.1)$ & $336(77.4)$ & \\
\hline \multicolumn{6}{|c|}{ Partner's Education Status $(n=3130)$} \\
\hline No education & 504 & $65(12.9)$ & $196(38.9)$ & $243(48.2)$ & \multirow[t]{4}{*}{$<0.001$} \\
\hline Primary & 840 & $81(9.6)$ & $252(30)$ & $507(60.4)$ & \\
\hline Secondary & 1867 & $80(40.3)$ & $397(21.3)$ & $1390(74.5)$ & \\
\hline Higher & 2626 & $17(2.3)$ & $105(13.9)$ & $632(83.8)$ & \\
\hline \multicolumn{6}{|l|}{ Sex of household head } \\
\hline Male & 2746 & $173(6.3)$ & $680(24.8)$ & $1893(68.9)$ & \multirow[t]{2}{*}{0.187} \\
\hline Female & 1181 & $79(6.3)$ & $279(22.1)$ & $902(71.6)$ & \\
\hline \multicolumn{6}{|l|}{ Healthcare Decision maker } \\
\hline Herself & 848 & $59(7)$ & $166(19.6)$ & $623(73.5)$ & \multirow[t]{3}{*}{0.003} \\
\hline Women and someone else & 1149 & $58(5)$ & $274(23.8)$ & $817(71.1)$ & \\
\hline Others & 1973 & $126(6.4)$ & $511(25.9)$ & $1336(67.7)$ & \\
\hline \multicolumn{6}{|l|}{ Exposure to Newspaper } \\
\hline Not at all & 3033 & $237(7.8)$ & $868(28.6)$ & $1928(63.6)$ & \multirow[t]{3}{*}{$<0.001$} \\
\hline Less than once a week & 791 & $14(1.8)$ & $81(10.2)$ & $696(88)$ & \\
\hline At least once a week & 182 & $1(0.5)$ & $10(5.5)$ & $171(94)$ & \\
\hline \multicolumn{6}{|l|}{ Exposure to Radio } \\
\hline Not at all & 1696 & $135(8)$ & $540(31.8)$ & $1021(60.2)$ & \multirow[t]{3}{*}{$<0.001$} \\
\hline Less than once a week & 1271 & $67(5.3)$ & $242(19)$ & $962(75.7)$ & \\
\hline At least once a week & 1039 & $50(4.8)$ & $177(17)$ & $812(78.2)$ & \\
\hline \multicolumn{6}{|l|}{ Exposure to Television } \\
\hline Not at all & 1519 & $168(11.1)$ & $501(33)$ & $850(56)$ & \multirow[t]{3}{*}{$<0.001$} \\
\hline Less than once a week & 893 & $43(4.8)$ & $217(24.3)$ & $633(70.9)$ & \\
\hline At least once a week & 1594 & $41(2.6)$ & $241(15.1)$ & $1312(82.3)$ & \\
\hline
\end{tabular}

visited for an antenatal check-up at least once during their pregnancy. Among the total women, $69.8 \%$ of total women have visited for ANC check-up four or more times as per the recommendation, while $6.3 \%$ of women had no ANC visits (Fig. 2).

The birth outcome being live was higher in the women who had visited for ANC check-up four or more times than that of women who went for ANC check-up less than four-times $\left(\chi^{2}: 14.742, p<0.001\right)$ (Table 2). For the women, who had visited for ANC check-up more than once or at least, most of the women had their first visit during the 3rd month of the pregnancy, followed by the 4th month and then 2nd month. Few women also had the 1 st visit on the 7 th, 8 th, or 9th month (Fig. 2).

\section{Multilevel logistic regression between ANC $4^{+}$and contextual and individual factors}

Table 3 presents the result of the multilevel logistic regression model for the frequency of ANC visits. Model 1 shows the effect of contextual factor (predisposing) on the propensity of completing four or more ANC visits, which predicted women from province 2, 6 and 7, and women coming from other ethnic backgrounds besides Brahmin/Chettri were significantly less likely to visit ANC 4 or more times. In model 2, the effect of contextual factors (predisposing and enabling) on the frequency of ANC visits where women from province 2 and 6 , and women from every ethnicity. As compared to Brahmin/ Chettri, all other ethnic pregnant women had a significantly low probability of going for at least a minimum recommended number of $\mathrm{ANC}$, while women from the middle and wealthy class were significantly more likely to go for four or more ANC check-ups.

Individual-level predisposing variables are incorporated in model 3 , and the result showed province, ethnicity, level of education, and age were significantly associated with the frequency of ANC visit. Women who had primary, secondary, or higher education had a significantly higher probability of going for ANC check-ups four or more times. Finally, both contextual (predisposing and enabling) and individual factors (predisposing and enabling) were incorporated in model 4, where 


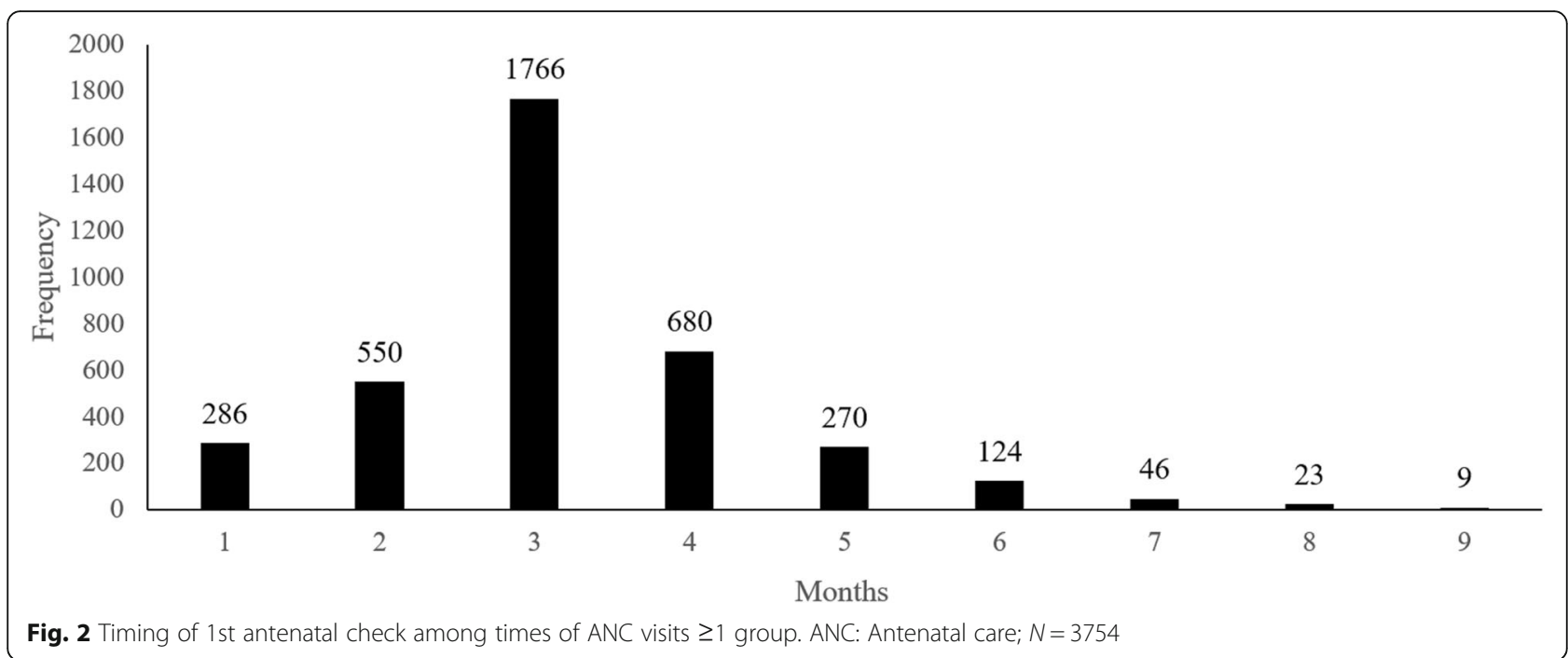

province, ethnicity, age, level of education (women's), partner's education and exposure to the newspaper, radio, and TV were significantly associated with the frequency of ANC visit. Pregnant women's partners who had received secondary or higher education were significantly more likely to go for the recommended number or more ANC check-ups.

Regarding variances for each of the random effects in the models, model 1 shows that most of the variation was observed at PSU within residence type, which was, even though decreasing across the subsequent model with the addition of individual factors. Decreasing variance at residence type also was observed through model 1 to model 4. Similarly, intra class correlation coefficient was reported to decreasing across the model 1 to model 4 .

\section{Discussion}

The study differs from other similar studies in terms of analysis; we have carried out multilevel logistic regression to analyze the relative contribution of contextual factors and individual factors $[8,12]$. The twofold analyses could contribute to defining an appropriate level of intervention and designing effective policies.

Our study, like other studies, shows that birth outcomes to be significantly better in women who visit ANC as per the recommendation [25-30]. Increased survival is one of the essential benefits of ANC to babies [31, 32]. Similarly, through this study, we found out the place of residence, age, religion, wealth index of the family, educational level, partner's education level, and

Table 2 Association of times of ANC visits with live birth

\begin{tabular}{lllll}
\hline Times of ANC visits & Total $(\boldsymbol{N}=4006)$ & Live birth (\%) & $x^{\mathbf{2}}$ & $\boldsymbol{p}$-value \\
\hline $0-3$ & 1211 & $1172(96.8)$ & & \\
$4+$ & 2795 & $2756(98.6)$ & 14.742 & 0.001 \\
\hline
\end{tabular}

exposure to multimedia was significantly associated with a higher frequency of ANC visits in both contextual and individual models.

Recent studies conducted in Ghana showed that women in urban areas have a higher socioeconomic status, which was positively associated with higher use of ANC services [33]. This phenomenon can be explained by the urban effect where half of the urban impact was described by wealth and education alone [33, 34]. In a study conducted in Mumbai, India also found out the customs as per ethnicity or religion to influence the uptake of maternal health care services, which were similar to our study [35-37].

Women who came from a wealthy background were more likely to go and get an ANC checkup for four or more times, which is similar to another study conducted in Nepal [8]. There have scarce studies to show the relationship between the province and service utilization. Other provinces of Nepal comprise of more developed districts compared to provinces 2 and 6 . Most districts in provinces 2 and 6 are relatively economically backward and geographically remote; longer the distance or difficulty the geography, women are less likely to go and use the services. Similarly, province 6 includes all of the remote western parts of Nepal, causing the rural-urban effect of lower service utilization in that part rural and economically backward provinces. Women in those parts gave birth in an animal shed due to the belief that deity would be angry if they would give birth at home [38], which could be the reason for lower education and economic status. Economic status directly affects the availability of services and education status of the women in the provinces and also affects the ability of a person to utilize the available services $[39,40]$.

The study also revealed that the strong association between the frequency of use of multimedia and ANC 
Table 3 Multilevel logistic regression of factors associated with ANC 4+

\begin{tabular}{|c|c|c|c|c|}
\hline Variables & Model 1 OR (95\%Cl) & Model 2 OR (95\%Cl) & Model 3 OR (95\%Cl) & Model 4 OR (95\%C \\
\hline \multicolumn{5}{|l|}{ Contextual variables } \\
\hline \multicolumn{5}{|l|}{ Predisposing variables } \\
\hline \multicolumn{5}{|l|}{ Provinces } \\
\hline \multicolumn{5}{|l|}{ Province 1 (ref) } \\
\hline Province 2 & $0.35(0.22-0.57)^{\mathrm{a}}$ & $0.35(0.22-0.54)^{a}$ & $0.44(0.28-0.67)^{\mathrm{a}}$ & $0.48(0.32-0.74)^{b}$ \\
\hline Province 3 & $1.11(0.68-1.8)$ & $1(0.63-1.56)$ & $1.04(0.66-1.64)$ & $1(0.63-1.57)$ \\
\hline Province 4 & $0.97(0.59-1.58)$ & $0.94(91.06-0.84)$ & $0.83(0.53-1.3)$ & $0.78(0.5-1.22)$ \\
\hline Province 5 & $0.89(0.56-1.4)$ & $0.83(0.54-1.27)$ & $0.9(0.59-1.37)$ & $0.93(0.61-1.41)$ \\
\hline Province 6 & $0.35(0.22-0.55)^{\mathrm{a}}$ & $0.44(0.28-0.69)^{\mathrm{a}}$ & $0.46(0.3-0.71)^{\mathrm{a}}$ & $0.46(0.3-0.71)^{c}$ \\
\hline Province 7 & $0.61(0.38-0.98)^{c}$ & $0.73(0.47-1.14)$ & $0.92(0.59-1.42)$ & $0.94(0.61-1.46)$ \\
\hline \multicolumn{5}{|l|}{ Ethnicity } \\
\hline \multicolumn{5}{|l|}{ Brahmin/Chettri (ref) } \\
\hline Janjati & $0.48(0.37-0.61)^{a}$ & $0.52(0.41-0.67)^{\mathrm{a}}$ & $0.66(0.51-0.85)^{b}$ & $0.67(0.52-0.87) b$ \\
\hline Dalit & $0.48(0.36-0.63)^{a}$ & $0.57(0.44-0.76)^{\mathrm{a}}$ & $0.82(0.62-1.09)$ & $0.88(0.66-1.18)$ \\
\hline Muslim & $0.34(0.19-0.61)^{\mathrm{a}}$ & $0.28(0.17-0.44)^{\mathrm{a}}$ & $0.49(0.31-0.79)^{\mathrm{b}}$ & $0.57(0.36-0.91)^{c}$ \\
\hline Others & $0.53(0.37-0.75)^{a}$ & $0.49(0.34-0.69)^{\mathrm{a}}$ & $0.67(0.47-0.97)^{c}$ & $0.74(0.51-1.07)$ \\
\hline \multicolumn{5}{|l|}{ Religion } \\
\hline \multicolumn{5}{|l|}{ Hindu (ref) } \\
\hline Non--Hindu & $0.92(0.65-1.29)$ & & & \\
\hline \multicolumn{5}{|l|}{ Enabling factors } \\
\hline \multicolumn{5}{|l|}{ Wealth Index of family } \\
\hline \multicolumn{5}{|l|}{ Poor (ref) } \\
\hline Middle & & $1.88(1.5-2.36)^{\mathrm{a}}$ & $1.6(1.27-2.03)^{a}$ & $1.38(1.08-1.76)$ \\
\hline Rich & & $2.87(2.29-3.6)^{\mathrm{a}}$ & $1.97(1.56-2.49)^{\mathrm{a}}$ & $1.53(1.19-1.99)$ \\
\hline \multicolumn{5}{|l|}{ Individual factors } \\
\hline \multicolumn{5}{|l|}{ Predisposing factors } \\
\hline Age & & & $0.95(0.94-0.96)^{\mathrm{a}}$ & $0.95(0.93-0.96)^{\mathrm{a}}$ \\
\hline \multicolumn{5}{|l|}{ Level of education } \\
\hline \multicolumn{5}{|l|}{ No education (ref) } \\
\hline Primary school & & & $1.64(1.32-2.03)^{\mathrm{a}}$ & $1.38(1.1-1.72)^{b}$ \\
\hline Secondary school & & & $2.78(2.26-3.43)^{a}$ & $1.87(1.47-2.36)^{a}$ \\
\hline Higher school & & & $7.7(5.37-11.04)^{\mathrm{a}}$ & $4.64(3.05-7.05)^{\mathrm{a}}$ \\
\hline \multicolumn{5}{|l|}{ Enabling factors } \\
\hline \multicolumn{5}{|l|}{ Level of partner's education } \\
\hline \multicolumn{5}{|l|}{ No education (ref) } \\
\hline Primary school & & & & $1.24(0.95-1.61)$ \\
\hline Secondary school & & & & $1.51(1.17-1.95)^{b}$ \\
\hline Higher school & & & & $1.45(1.01-2.06)^{c}$ \\
\hline \multicolumn{5}{|l|}{ Healthcare Decision maker } \\
\hline \multicolumn{5}{|l|}{ Herself (ref) } \\
\hline Women and someone else & & & & $0.94(0.74-1.2)$ \\
\hline Others & & & & $1.06(0.86-1.32)$ \\
\hline
\end{tabular}

\section{Exposure to Media}

Less than once a week (ref) 
Table 3 Multilevel logistic regression of factors associated with ANC 4+ (Continued)

\begin{tabular}{|c|c|c|c|c|}
\hline Variables & Model 1 OR $(95 \% \mathrm{Cl})$ & Model 2 OR (95\%Cl) & Model 3 OR (95\%Cl) & Model 4 OR $(95 \% \mathrm{Cl})$ \\
\hline At least once a week & & & & $1.86(0.94-3.66)^{b}$ \\
\hline Variance at individual: (PSU: residence (urban/rural): PSU) & 0.0006 & 0.0002 & $<0.00001$ & $<0.00001$ \\
\hline Variance at PSU: residence (urban/rural) & 0.75 & 0.62 & 0.53 & 0.51 \\
\hline Variance at residence (urban/rural) & 0.123 & 0.05 & 0.021 & 0.02 \\
\hline ICC & 0.21 & 0.17 & 0.143 & 0.13 \\
\hline
\end{tabular}

Model 1: mutually adjusted for contextual predisposing variables

Model 2: mutually adjusted for contextual predisposing and enabling variables

Model 3: mutually adjusted for contextual predisposing and enabling variables, and individual predisposing variables

Model 4: mutually adjusted for contextual predisposing and enabling variables, and individual predisposing and enabling variables

Ref: Reference, OR Odds ratio, CI Confidence interval, PSU Primary sampling unit, ICC Intra class correlation coefficient

${ }^{\mathrm{c}} P \leq 0.05 ;{ }^{\mathrm{b}} P \leq 0.01 ;{ }^{\mathrm{a}} P \leq 0.001$

service utilization. Even if the women used any form of multimedia even less than once a week, they were at better odds of visiting for ANC four times or more. Hence, we concluded that exposure to multimedia could affect the service utilization of women in terms of maternal health. The exposure to multimedia and the utilization of maternal health services is understudied in Nepal. However, a study showed a 6-fold increase in the use of ANC with exposure to multimedia like television and radio [41]. Similar results have been observed in the studies conducted in countries like Bangladesh, India, and Uganda multimedia having a positive impact on ANC service utilization [18, 42-44].

Hence, better antenatal care results in a better birth outcome, which directly or indirectly contributes to maternal as well as child health. Various studies have explored the factors associated with the use of maternal services and have rooted common factors such as age, religion, economic status, etc. Our research has also observed the use of multimedia in relation to ANC visit, and we strongly suggest utilizing factors such as multimedia use to address the gap that lies in the utilization of ANC as per recommendation. A further study focusing on the use and content of media could lead us to a new direction on efforts to address the gaps associated with this.

The present study is a cross-sectional study where we cannot establish a causal relationship. The study is a retrospective study; hence, there are chances of recall bias whereby we have only analyzed the data regarding the most recent pregnancy within the past 5 years to minimize the recall bias. Similarly, this study did not take into account other relevant factors associated with the quality of antenatal care, such as the timing of visits and care practice during the visits.

However, we used NDHS data where the samples were taken across the nation so the findings can be generalized to the entire country. Also, the methodology used in NDHS is precise with stratified multilevel sampling and the use of the standard questionnaire [15]. Similarly, training was provided to enumerators before the data collection. All the ethical issues have been addressed before the collection of the data by DHS, and approval from institutional review board was taken [15].

\section{Conclusions}

This study shows a strong association between both contextual and individual determinants and frequency of ANC visits. Contextual factors such as province, household wealth index, ethnicity, and individual level predisposing factors such as age along with enabling factors (partner's education level, exposure to multimedia) contributed to the recommended number of ANC visits. Thus, we conclude that ANC attendance is vital for live birth, and intervention target at various levels is recommended.

Effective National Safe Motherhood Policy meets SDGs' target by addressing healthy reproductive needs. To make National Safe Motherhood policy effective, the factors associated with 4+ ANC visit needs to be addressed appropriately with developing special health promotion program with a focus on the vulnerable and disadvantaged. Moreover, the flexible use of multimedia should be encouraged to improve maternal health literacy.

\section{Abbreviations \\ ANC: Antenatal Care; Cl: Confidence Interval; DHS: Demographic Health Survey; GDP: Gross Development Product; MMR: Maternal Mortality Rate; MDGs: Millennium Development Goals; NDHS: Nepal Demographic and Health Survey; OR: Odds Ratio; PSUs: Primary Sampling Units; SDG: Sustainable Development Goal; USAID: United States Aid for International Development; WHO: World Health Organization}

\section{Acknowledgments}

The authors express their gratitude to The DHS Program, ICF, 530 Gaither Road Suite 500, Rockville, MD 20850, the USA for conducting a nationwide survey and making it available for the further analysis. Thank you, associates, Professor Lu Hui (Nanjing Medical University), for providing the technical guidance.

Authors' contributions

$\mathrm{BN}$ and SR contributed to the concept development and data analysis along with the write-ups. TBB guided this work and provided the required technical inputs in data analysis. BN, SGC and TBB prepared the manuscript. All 
four authors gave final approval and agreed to be accountable for all aspects of work, ensuring integrity and accuracy.

\section{Funding}

The authors did not receive any financial support for the research, authorship, and/or publication of this article.

\section{Availability of data and materials}

The datasets generated and analyzed during the current study are available in the demographic and health survey (DHS) programme repository, www. dhsprogram.com/data/dataset_admin/login_main.cfm.

\section{Ethics approval and consent to participate}

The data collection for the NDHS, 2016, was ethically approved by the Nepal Health Research Council (NHRC), which is a national level government organization leading in research activities in Nepal. Similarly, ethical clearance was also obtained from ICF Macro Institutional Review Board, Maryland, USA. Data were collected after an online application was submitted to the Demographic Health Survey (DHS) program explaining the purpose of the study, intended use, and people who would have access over the data [15] After the review of the online application, permission had been granted from the monitoring and evaluation body of DHS globally, Monitoring and Evaluation to Access and Use Results Demographic and Health Survey (MEASURE DHS), to use the data set for this study. The NDHS, 2016 data are publicly available at the USAID DHS program (at http://dhsprogram.com/ data) in different formats. This is a secondary analysis of publicly available data; hence an independent ethical approval was not required.

\section{Consent for publication}

Not applicable.

\section{Competing interests}

The authors declare that they have no competing interests.

\section{Author details}

${ }^{1}$ Institute of Medicine, Tribhuwan University, Maharajgunj, Kathmandu, Nepal. ${ }^{2}$ University of Oslo, Oslo, Norway. ${ }^{3}$ BP Koirala Institute of Health Science, Dharan, Nepal.

Received: 11 February 2020 Accepted: 30 April 2020

Published online: 19 May 2020

\section{References}

1. UNICEF Annual Report 2013 - Indonesia UNICEF I. 2012. https://www.unicef. org/about/annualreport/files/Indonesia_COAR_2013.pdf. Accessed 22 Oct 2018.

2. Global Health Observatory data. World Health Organization. www.who.ino/ gho/maternal_health/en/. 2015. Accessed 22 Oct 2018.

3. Antenatal Care. UNICEF. https://data.unicef.org/topic/maternal-health/ antenatal-care/. 2018. Accessed 22 Oct 2018.

4. $\mathrm{WHO}$ recommendations on antenatal care for a positive pregnancy experience. World H, Organization. 2016. https://www.who.int/ reproductivehealth/publications/maternal_perinatal_health/anc-positivepregnancy-experience/en/. Accessed 25 Oct 2018.

5. The Sustainable Development Goals and Maternal Mortality. https://www. mhtf.org/topics/the-sustainable-development-goals-and-maternal-mortality/. Accessed 2 Nov 2019.

6. SDG 3: Ensure healthy lives and promote wellbeing for all at all ages. https://www.who.int/sdg/targets/en/. Accessed 2 Nov 2018.

7. The partnership for maternal newborn and child health. https://www.who. int/pmnch/media/press_materials/fs/about_mdgs/en/. Accessed 3 Nov 2018.

8. Neupane S, Nwaru BI. Impact of prenatal care utilization on infant care practices in Nepal: a national representative cross-sectional survey. Eur J Pediatr. 2014:173(1):99-109.

9. MCCURDY RJ, Kjerulff $\mathrm{KH}$, Zhu J. Prenatal care associated with reduction of neonatal mortality in sub-Saharan Africa: evidence from demographic and health surveys. Acta Obstet Gynecol Scand. 2011;90(7):779-90.

10. Ghosh R, Sharma AK. Intra-and inter-household differences in antenatal care, delivery practices and postnatal care between last neonatal deaths and last surviving children in a peri-urban area of India. J Biosoc Sci. 2010;42(4):51130.

11. Karkee R, Lee AH, Binns CW. Why women do not utilize maternity services in Nepal: a literature review. WHO South East Asia J Public Health. 2013:2(3):135.

12. Kathmandu N. Maternal and child health in Nepal: the effects of caste, ethnicity, and regional identity; 2013

13. Annual Report F/Y 2068/69. Government of Nepal, MoHP, Department of health services. 2012/2013. https://dohs.gov.np/wp-content/uploads/2016/ 06/Annual_Report_FY_2071_72.pdf. Accessed 4 Nov 2019.

14. Powell-Jackson T, Hanson K. Financial incentives for maternal health: impact of a national programme in Nepal. J Health Econ. 2012;31(1):271-84.

15. Demographic and Health Survey Nepal. 2017. Accessed 8 Oct 2018.

16. Mehata S, Paudel YR, Dariang M, Aryal KK, Lal BK, Khanal MN, Thomas D. Trends and inequalities in use of maternal health care services in Nepal: strategy in the search for improvements. Biomed Res Int. 2017;2017: 5079234.

17. Joshi C, Torvaldsen S, Hodgson R, Hayen A. Factors associated with the use and quality of antenatal care in Nepal: a population-based study using the demographic and health survey data. BMC Pregnancy Childbirth. 2014;14(1):94

18. Edward B. Factors influencing the utilisation of antenatal care content in Uganda. Australas Med J. 2011;4(9):516.

19. Tran TK, Gottvall K, Nguyen HD, Ascher H, Petzold M. Factors associated with antenatal care adequacy in rural and urban contexts-results from two health and demographic surveillance sites in Vietnam. BMC Health Serv Res. 2012;12(1):40

20. Babitsch B, Gohl D, von Lengerke T. Re-revisiting Andersen's Behavioral Model of Health Services Use: a systematic review of studies from 1998 2011. Psychosoc Med. 2012;9:Doc11.

21. Tesfaye G, Chojenta C, Smith R, Loxton D. Application of the AndersenNewman model of health care utilization to understand antenatal care use in Kersa District, Eastern Ethiopia. PloS one. 2018;13(12):e0208729.

22. Tejeda S, Thompson B, Coronado GD, Martin DP, Heagerty PJ. Predisposing and enabling factors associated with mammography use among Hispanic and non-Hispanic white women living in a rural area. J Rural Health. 2009; 25(1):85-92

23. Tesfaye G, Chojenta C, Smith R, Loxton D. Application of the AndersenNewman model of health care utilization to understand antenatal care use in Kersa district, Eastern Ethiopia. PLoS One. 2018;13(12):e0208729.

24. Nepal In Data. www.nepalindata.com. Accessed 15 Dec 2018.

25. Main DM. The epidemiology of preterm birth. Clin Obstet Gynecol. 1988; 31(3):521-32.

26. Villar J, Ba'ageel H, Piaggio G, Lumbiganon P, Belizán JM, Farnot U, AlMazrou Y, Carroli G, Pinol A, Donner A. WHO antenatal care randomised tria for the evaluation of a new model of routine antenatal care. Lancet. 2001; 357(9268):1551-64.

27. What is the efficacy/effectiveness of antenatal care and the financial and organizational implications? Organization WH. 2003. http://www.euro.who. int/data/assets/pdf_file/0007/74662/E82996.pdf. Accessed 18 Dec 2018.

28. Prual A, De Bernis L, El Joud DO. Potential role of prenatal care in reducing maternal and perinatal mortality in sub-Saharan Africa. J Gynecol Obstet Biol Reprod (Paris). 2002:31(1):90-9.

29. Bhutta ZA, Darmstadt GL, Hasan BS, Haws RA. Community-based interventions for improving perinatal and neonatal health outcomes in developing countries: a review of the evidence. Pediatrics. 2005;115(2 Suppl):519-617.

30. Tuladhar H, Dhakal N. Impact of antenatal care on maternal and perinatal utcome: a study at Nepal medical college teaching hospital. Nepal J Obstet Gynaecol. 2012;6(2):37-43.

31. Adam T, Lim SS, Mehta S, Bhutta ZA, Fogstad H, Mathai M, Zupan J, Darmstadt GL. Achieving the millennium development goals for health: cost effectiveness analysis of strategies for maternal and neonatal health in developing countries. BMJ. 2005;331(7525):1107-9.

32. Millennium Development Goals. https://www.who.int/topics/millennium_ development goals/about/en/. Accessed 18 Dec 2018.

33. Afulani PA. Rural/urban and socioeconomic differentials in quality of antenatal care in Ghana. PLoS One. 2015:10(2):e0117996.

34. Adewuyi EO, Auta A, Khanal V, Bamidele OD, Akuoko CP, Adefemi K, Tapshak SJ, Zhao Y. Prevalence and factors associated with underutilization of antenatal care services in Nigeria: a comparative study of rural and urban residences based on the 2013 Nigeria demographic and health survey. PLoS One. 2018;13(5):e0197324. 
35. Das S, Bapat U, More NS, Chordhekar L, Joshi W, Osrin D. Prospective study of determinants and costs of home births in Mumbai slums. BMC Pregnancy Childbirth. 2010;10(1):38.

36. National Population and Housing Census 2011. National Planning comission Secretariat CBoS, GON. 2011. https://cbs.gov.np/. Accessed 5 Jan 2019.

37. Harris R, Gibbs D, Mangin-Heimos K, Pineda R. Maternal mental health during the neonatal period: relationships to the occupation of parenting. Early Hum Dev. 2018;120:31-9.

38. Thapa N, Chongsuvivatwong V, Geater AF, Ulstein M. High-risk childbirth practices in remote Nepal and their determinants. Women Health. 2001; 31(4):83-97.

39. Wagle RR, Sabroe S, Nielsen BB. Socioeconomic and physical distance to the maternity hospital as predictors for place of delivery: an observation study from Nepal. BMC Pregnancy Childbirth. 2004;4(1):8.

40. Chaudhary P. Accidental out-of-hospital deliveries: factors influencing delay in arrival to maternity hospital. Kathmandu Univ Med J. 2005;3(2):115-22.

41. Acharya D, Khanal V, Singh JK, Adhikari M, Gautam S. Impact of mass media on the utilization of antenatal care services among women of rural community in Nepal. BMC Res Notes. 2015;8(1):345.

42. Kulkarni M, Nimbalkar M. Influence of socio-demographic factors on the use of antenatal care. Ind J Prev Soc Med. 2008:39(3):98-102.

43. Islam MR, Odland JO. Determinants of antenatal and postnatal care visits among Indigenous people in Bangladesh: a study of the Mru community. Rural Remote Health. 2011;11(2):1672.

44. Ghosh D. Effect of mothers' exposure to electronic mass media on knowledge and use of prenatal care services: a comparative analysis of Indian states. Prof Geogr. 2006;58(3):278-93.

\section{Publisher's Note}

Springer Nature remains neutral with regard to jurisdictional claims in published maps and institutional affiliations.

Ready to submit your research? Choose BMC and benefit from:

- fast, convenient online submission

- thorough peer review by experienced researchers in your field

- rapid publication on acceptance

- support for research data, including large and complex data types

- gold Open Access which fosters wider collaboration and increased citations

- maximum visibility for your research: over $100 \mathrm{M}$ website views per year

At BMC, research is always in progress.

Learn more biomedcentral.com/submissions 